\title{
Grupo de estudos e pesquisas sobre a psicopedagogia escolar: seus saberes e suas
}

\author{
práticas
}

\section{Group of study and research about school psychopedagogy: Its knowledge and practices}

\author{
Maria Irene Miranda \\ Universidade Federal de Uberlândia
}

\begin{abstract}
Resumo
O GEPPE (Grupo de Estudos e Pesquisas sobre a Psicopedagogia Escolar) foi criado em 2009 no âmbito da FACED/UFU (Faculdade de Educação da Universidade Federal de Uberlândia) com o objetivo de estudar e pesquisar os processos de aprendizagem e seus possíveis obstáculos, articulando ações entre a universidade e escolas públicas. As atividades desenvolvidas contemplam o ensino (graduação e pós-graduação), a pesquisa (iniciação científica e mestrado) e a extensão (congresso, cursos e atendimentos psicopedagógicos). Destacam-se nesse trabalho as pesquisas desenvolvidas por meio da iniciação científica por alunos da graduação em pedagogia, sob a supervisão de um professor orientador.

Palavras chaves: Psicopedagogia, aprendizagem, pesquisa de intervenção
\end{abstract}

\begin{abstract}
GEPPE (Grupo de Estudos e Pesquisas sobre Psicopedagogia Escolar) (Study Group of Researches about school Psychopedagogy) was created in 2009 within FACED/UFU (Faculdade de Educação da Universidade Federal de Uberlândia) with the objective of studying and doing researches of the learning processes and its possible obstacles, articulating actions between the University and public schools. The activities developed persue the learning, (graduation and post-graduation), the research (scientific initiation and masters degree) and the extension (congress, courses and psychopedagogical attendance). This work highlights the reaserches developed through the scientific initiation by students from the gradutaion of pedagogy under the supervision of a professor.

Keywords: Psychopedagogy, Learning, Intervention research.
\end{abstract}

No ano de 2009, no âmbito da FACED/UFU (Faculdade de Educação da Universidade Federal de Uberlândia), foi criado e institucionalizado o GEPPE (Grupo de Estudos e Pesquisas sobre a Psicopedagogia Escolar), sob a iniciativa da profa. Dra. Maria Irene Miranda. O grupo é composto por alunos da graduação (pedagogía), pós-graduação (especialização e mestrado), professores, pedagogos e psicopedagogos.
Conforme previsto em seu projeto de criação o funcionamento do GEPPE está pautado nos seguintes objetivos:

- Possibilitar a realização e socialização de estudos, pesquisas e ações referentes a Psicopedagogia Escolar;

- Desenvolver Estudos de Caso Psicopedagógico no âmbito da Faculdade de Educação;

- Favorecer a melhoria da qualidade do ensino oferecido nas escolas, por meio de projetos de intervenção psicopedagógica que visam promover a aprendizagem e o sucesso escolar dos alunos;

- Possibilitar a interlocução entre a universidade e demais instituições de ensino.

As atividades desenvolvidas pelo grupo compreendem o ensino (graduação e pós-graduação), a pesquisa (iniciação científica e mestrado) e a extensão (congresso, cursos e atendimentos psicopedagógicos), contemplando, assim, o tripé organizador da função social da universidade.

Destacam-se nesse trabalho as pesquisas desenvolvidas por meio da iniciação científica (IC) com alunos bolsistas do curso de graduação em pedagogia, sob a supervisão de um professor orientador. As bolsas são custeadas pelas agências de fomento: $\mathrm{CNPq}$ (Conselho Nacional de Desenvolvimento Científico e Tecnológico) e FAPEMIG (Fundação de Amparo à Pesquisa de Minas Gerais). Após aprovação em processo seletivo via Editais do PIBIC (Projeto Institucional de Bolsa de Iniciação Científica) das referidas agências, os discentes passam a integrar o GEPPE e juntamente com o professor orientador realizam atendimento psicopedagógico para desenvolver um estudo de caso.

Os atendimentos psicopedagógicos compõem as atividades de extensão do GEPPE, portanto são oferecidos gratuitamente a pessoas da comunidade com queixas em seu processo de aprendizagem. 
Uma vez definido o atendimento tem início a pesquisa por meio do Estudo de Caso Psicopedagógico.

\section{Método}

Devido a importância da compreensão do método para realização da pesquisa, os alunos da iniciação científica são orientados quanto ao procedimento metodológico, assim como participam no GEPPE das discussões de encaminhamento da pesquisa.

Enquanto pesquisador é necessário saber que a produção do conhecimento psicopedagógico compreende um percurso metodológico coerente aos seus princípios epistemológicos. Sendo assim, após realizar estudos sobre os métodos de pesquisa faz-se opção pelo estudo de caso.

O estudo de caso é uma modalidade de pesquisa que busca conhecer uma situação ou fato específico, singular que apresenta características únicas, mas que faz parte de um todo, é digno de ser estudado em sua complexidade. $\mathrm{O}$ estudo de caso descreve, analisa e desencadeia reflexões sobre um fato ou fenômeno único, considerando suas múltiplas e relacionadas dimensões, assim como sua dinâmica naturalística.

De natureza qualitativa, um estudo de caso não comporta postura de neutralidade, o pesquisador se posiciona diante do caso. Sendo assim, o aluno da iniciação científica é orientado no planejamento e desenvolvimento de um esquema de trabalho flexível e aberto, com sensibilidade para detectar as especificidades do contexto.

Na perspectiva psicopedagógica a pertinência dessa modalidade de investigação científica está na singularidade que caracteriza cada pessoa em processo de aprendizagem ou pessoa aprendente. Cada ser é único e apresenta especificidades que precisam ser consideradas, o que exige do pesquisador o olhar e a escuta sensível.

Yin (2005) afirma que os estudos de caso representam a estratégia preferida para questões do tipo "como" e "por que", quando o pesquisador não controla os acontecimentos e quando o foco está em fenômenos contemporâneos inseridos em contexto da vida real. Dessa forma, a problematização da pesquisa psicopedagógica está relacionada a aprendizagem: Por que a pessoa não aprende? Quais são os fatores intervenientes da não-aprendizagem? Como favorecer a aprendizagem?

Uma pesquisa que tem por objetivo elucidar e explicar os porquês, principalmente quando em se tratando de aprendizagem e não aprendizagem podem ser tantos os porquês, exige a definição de uma linha de pensamentos e convicções para fins de possíveis análises e intervenções. Ciente dessa necessidade, o GEPPE busca compreender os fatores desencadeadores das supostas dificuldades, o que traduz-se em um amálgama de ideias para prováveis formas de contribuir para a melhoria da situação.

Partindo do pressuposto de que a aprendizagem é inerente a condição humana e com base na problematização, o objetivo da pesquisa é promover a aprendizagem, superando as dificuldades existentes no processo de construção do conhecimento. Para tanto, recorre-se ao diagnóstico ou avaliação psicopedagógica, cujo processo consiste no uso de instrumentos específicos.

Por fim, a opção metodológica não é aleatória à medida que se relaciona estreitamente com as concepções de mundo, de homem e de conhecimento. Por outro lado orienta o processo investigativo, a tomada de decisões, a construção de hipóteses, a definição de técnicas e instrumentos, a análise dos dados.

\section{Os instrumentos}

Para levantamento dos dados por meio da avaliação psicopedagógica são utilizados instrumentos próprios da psicopedagogia: a anamnese, a entrevista com a pessoa aprendente, entrevista com professores, atividades pedagógicas, técnicas psicopedagógicas, jogos, atividades lúdicas e outros que se fizerem necessários. Nesse momento é possível buscar a contribuição de outros profissionais (psicólogos, neurologistas, fonoaudiólogos) para construir uma visão mais sistêmica da pessoa aprendente.

É importante que o aluno de IC conheça os recursos disponíveis para construção dos dados. Para tanto participa de estudos no GEPPE que abordam os conceitos, objetivos e procedimentos de uso dos instrumentos.

A anamnese consiste de uma entrevista com a familia para conhecer a história de vida dos sujeitos aprendentes. Esse instrumento registra dados desde a gestação, o nascimento até as características atuais de desenvolvimento. E ainda oferece informações quanto as relações estabelecidas no contexto familiar.

A entrevista com a pessoa aprendente é um conjunto de questões que visam conhecer o sujeito, portanto contemplam aspectos objetivos e subjetivos de sua vida cotidiana em diferentes contextos (escola, familia, amigos).

$\mathrm{Na}$ entrevista com professores as perguntas referem-se a aspectos da vida escolar: os conteúdos, os procedimentos metodológicos e avaliativos. E, também, busca conhecer as expectativas em relação ao aluno. Os pontos que permeiam a relação ensinante-aprendente.

As atividades pedagógicas envolvem a leitura, a escrita, resolução de situações problema, buscando conhecer como o sujeito organiza o pensamento para aprender. Quais são suas hipóteses em relação ao objeto de conhecimento, os esquemas mentais disponíveis a aquisição de novas concepções.

As técnicas psicopedagógicas consistem de testes projetivos, por meio dos quais o sujeito projeta suas vivências e revela aspectos de seu psiquismo e de sua subjetividade. Qual tipo de sentimento envolve sua relação com o conhecimento? Existe envolvimento afetivo/emocional com a aprendizagem?

Os jogos e as atividades lúdicas revelam atitudes, posturas, movimentos corporais, habilidades psicomotoras, cognitivas, afetivas, relacionais, dentre 
outros. Ao jogar e brincar o sujeito aprendente mostra como se relaciona com a realidade, lida com seus conflitos e fantasias, desvelando aspectos de sua cognição, emoção e socialização.

Os relatórios de outros profissionais enriquecem a informações à medida que oferecem o olhar para o sujeito aprendente em diferentes vertentes; articulando pontos de vista de áreas distintas.

De acordo com o perfil do caso outros instrumentos podem ser utilizados: testes de inteligência, produção de desenhos livres e dirigidos, análise do material escolar, testes psicomotores, conversas informais, observação sistemática.

Não há supremacia entre os instrumentos, todos têm a sua relevância, principalmente quando trabalhados de forma articulada, pois isoladamente nenhum é suficiente para revelar a riqueza e complexidade dos dados.

$\mathrm{Na}$ utilização dos instrumentos são necessários alguns cuidados básicos (Miranda, 2016):

- Explicar ao sujeito o objetivo do trabalho, solicitando sua contribuição;

- Escolher dia, horário e local adequados;

- Solicitar permissão para gravar ou filmar;

- Estabelecer um diálogo, não ficar preso ao instrumento;

- Explicar a solicitação ou consigna quantas vezes se fizer necessário;

- Oferecer a opção ao sujeito de não participar da atividade proposta;

- Não ter expectativas em relação as respostas e não esboçar qualquer tipo de reação, positiva ou negativa, mediante os resultados das produções;

- Não interromper o sujeito em sua produção ou fala.

Com base no estudo dos instrumentos, o aluno de IC realiza o diagnóstico ou avaliação psicopedagógica, utilizando aqueles mais pertinentes ao perfil do sujeito atendido. Isso significa que nem todos os instrumentos disponíveis são utilizados; são selecionados os que podem oferecer dados mais significantes ao desvelamento do caso.

Mesmo havendo um cronograma de doze meses para realização da pesquisa (com possibilidade de dilação), não há como prever ou definir a priori o tempo de aplicação dos instrumentos, pois dependerá do ritmo e do envolvimento da pessoa em atendimento.

Finalizados os instrumentos, conhecidos e organizados os dados é necessário buscar os seus significados; tem-se início, portanto, a fase de análise, a qual exige leituras e estudos sistematizados do grupo, uma vez que analisar de forma equivocada compromete toda intervenção e leva a resultados indesejados.

\section{Os participantes da pesquisa}

Participam da avaliação psicopedagógica o sujeito aprendente, sua familia e seus professores; todos são participantes da pesquisa.
O sujeito aprendente apresenta uma demanda relacionada a aprendizagem, principalmente no âmbito escolar, motivo pelo qual a queixa é oriunda dos professores e/ou da familia.

Considerando os professores como mediadores do processo de construção do conhecimento, ouvi-los em relação ao sujeito em situação de aprendizagem é imprescindível. Da mesma forma, conhecer os vínculos familiares torna-se fundamental, à medida que a familia também é referência para constituição do sujeito.

\section{A análise dos dados}

A análise de dados é um dos momentos mais complexos da pesquisa e que exige um olhar crítico e teoricamente fundamentado. Não é possível uma neutralidade nesse "olhar", pois toda leitura constitui uma interpretação e compreensão, de natureza objetiva e subjetiva.

Para proceder a análise o grupo retoma as questões problematizadoras e os objetivos da pesquisa. Dessa forma, busca nos dados os elementos necessários à construção de respostas. Para Moroz e Gianfaldoni (2002) é o momento de tornar os dados inteligíveis, ou seja, organizá-los de forma a propor uma explicação pertinente àquilo que se quer investigar, pois um conjunto de informações desorganizadas não é útil, não oferece uma visão real dos resultados.

Sendo assim, utiliza-se da técnica de triangulação de dados, com vistas à fidedignidade da realidade verificada. Essa técnica é uma forma de favorecer as avaliações de dados construídos a fim de assegurar o esclarecimento do problema da pesquisa. O diálogo entre os dados possibilita segurança no resultado das análises. Para Triviños (1987) a triangulação amplia a descrição, explicação e compreensão do foco em estudo.

Por meio de leituras, releituras e triangulações os dados são organizados em unidades definidas por um tema, uma palavra ou uma frase relacionada a problematização e objetivos da pesquisa. Assim são constituidas as categorias de análise, articulando e sistematizando os dados para construção de um sistema explicativo do objeto de investigação.

A constituição das categorías não é um movimento linear de transcrição dos dados, mas um processo dinâmico, pautado em discussões, conflitos, divergências e convergências, principalmente quando acontece no grupo.

Em se tratando do estudo de caso psicopedagógico, que tem como objeto o processo de aprendizagem e suas dificuldades, os dados tendem a desvendar os aspectos que constituem a não aprendizagem. Nesse momento é imprescindível a interlocução com o referencial teórico que referenda as inferências e considerações. Dessa forma o grupo retoma a bibliografía pertinente e produz os seus conhecimentos sobre o aprender e não aprender. A aprendizagem não é um processo simples de entender ou estudar. Portanto, o papel da teoria é fundamental, a cada momento em que é evocada, estrutura e organiza o dado. 
As sistematizações construidas não comportam análises estáticas e nem estão pautadas no princípio da certeza, pois ficam evidentes as contradições e complexidades que envolvem os sujeitos aprendentes e os sujeitos ensinantes.

Após analisar e sistematizar os dados o grupo dispõe de elementos para produzir as ações de intervenção que visam restituir o sujeito de sua capacidade e direito de aprender.

A intervenção consiste em um conjunto de atividades que objetivam promover a aprendizagem, para tanto envolvem, além do sujeito aprendente, sua familia e seus professores.

No decorrer dos atendimentos psicopedagógicos o aluno de IC desenvolve ações de natureza pedagógica e psicopedagógica, planejadas em conformidade com as demandas analisadas por meio dos dados obtidos no diagnóstico. É comum o uso de jogos e atividades lúdicas, envolvendo a leitura, a escrita e o raciocinio lógico matemático. Naturalmente que para cada caso em estudo é realizado um planejamento, buscando atuar em conformidade com as especificidades de cada aprendente. A intervenção é um trabalho individual, realizado no âmbito da universidade, três vezes por semana, com sessões de sessenta minutos.

Um aspecto que não pode ser negligenciado é a abordagem da autoestima, visto que, quase sempre, os sujeitos que apresentam comprometimento acadêmico tendem a manifestar comportamentos de angústia, insegurança e falta de iniciativa, o que repercute em sua aprendizagem e na qualidade das demais relações sociais.

O diálogo com a escola da pessoa em atendimento é realizado por meio de visitas a instituição para reunião com os educadores (professores, pedagogos, diretores). Esses momentos são fundamentais para o éxito da intervenção, pois faz-se necessária uma parceria em prol do desenvolvimento e da aprendizagem. Nas reuniões os professores relatam sobre o dia a dia do sujeito em sala de aula, abordando principalmente as dificuldades existentes. Observa-se que a escola raramente realiza uma autoavaliação. Normalmente a instituição não se vê como interveniente na situação de não aprendizagem dos alunos. Assim, torna-se pertinente uma discussão/reflexão dos principios interacionistas, segundo os quais o aluno se constitui nas relações, portanto não é o uníco responsável por seu desempenho acadêmico.

São comuns as queixas dos docentes que, quase sempre, afirmam não saber como lidar com o aluno que não aprende. As queixas envolvem também as famílias, consideradas omissas e ausentes. $\mathrm{O}$ espaço de reuniões é um momento de trocas e reflexões sobre o caso em estudo. Além de serem ouvidos, os professores ficam sabendo do trabalho desenvolvido na intervenção psicopedagógica. E ainda recebem sugestões de atividades pedagógicas a serem trabalhadas nas aulas com todos os alunos. Observa-se nos professores a necessidade de serem ouvidos enquanto falam de sua prática. Nem todos são receptivos ou desenvolvem as sugestões psicopedagógicas, no entanto a possibilidade de dialogar e refletir acerca do caso abre novas perspectivas ao trabalho docente.

A familia está também envolvida na intervenção, e não podia ser diferente. Ao lado da escola, é uma instituição que promove aprendizagens desde a mais tenra idade. Sendo assim, o sujeito aprendente tem sua familia como referência de princípios, valores, crenças, posturas. Aqueles que convivem com o sujeito precisam ter consciência de seu papel de mediador na constituição do aprender. Nesse sentido são compartilhadas orientações e sugestões sobre como proceder no acompanhamento acadêmico, sem negligenciar os vínculos afetivos que permeiam qualquer relação de ensino e aprendizagem.

A periodicidade das reuniões com a escola e a familia depende das demandas sugeridas no decorrer dos atendimentos.

Quanto ao tempo de intervenção, devido as especificidades do sujeitos, não há como prever, pois alguns casos são trabalhados em poucos meses, enquanto outros necessitam de um ano ou mais.

Os atendimentos são encerrados quando o sujeito revela autonomia de pensamento e possibilidades de prosseguir em seus percursos formativos sem contar com acompanhamento e mediação psicopedagógica.

\section{Os resultados obtidos}

O GEPPE realiza análise dos resultados obtidos de forma processual e ao final da intervenção.

A análise processual refere-se ao acompanhamento paralelo as ações de intervenção desenvolvidas pelo aluno de IC. Nas reuniões de estudo as discussões são direcionadas por questões relevantes: Como o sujeito aprendente se envolve com a proposta? O objetivo previsto com a atividade foi alcançado? $\mathrm{O}$ trabalho favoreceu a aprendizagem? Ao final de um bimestre o que pode ser observado em termos de evolução? Será necessário rever o planejamento?

As questões acima pontuadas orientam o olhar para o sujeito em seu processo de construção do conhecimento. Não há expectativas estabelecidas a priori em relação aos avanços. O trabalho é desenvolvido no ritmo do aprendente, respeitando suas conquistas. Havendo necessidades, as atividades de intervenção são replanejadas.

Ao final da intervenção a análise dos resultados visa respaldar o desligamento do sujeito dos atendimentos. Dessa forma é realizado um novo diagnóstico, o qual é confrontado com o primeiro e com as atividades processuais. Constatando-se autonomía, o sujeito é desligado. Para tanto, as dificuldades e conflitos que caracterizavam sua relação com a aprendizagem precisam estar superados. Por exemplo, um sujeito que apresentava dificuldades de leitura e escrita, queixa recorrente nos atendimentos psicopedagógicos, precisa ter construido os conceitos subjacentes ao sistema de funcionamento da língua escrita, a ponto de ser capaz de ler e interpretar um texto, assim como se expressar por meio da escrita.

Os resultados obtidos com a pesquisa são provisórios e relativos, uma vez que o sujeito aprendente está 
inserido e interagindo em um contexto dinâmico, cujo movimento pode favorecer avanços e recuos. No entanto, de uma forma geral é possivel constatar empíricamente um principio básico da psicopedagogia: aprender é inerente a condição humana, ou seja, todos podem aprender, desde que a mediação seja pertinente e coerente a realidade biopsicossocial do aprendente. A experiência nos atendimentos revela que mediante o desenvolvimento de uma intervenção sempre ocorrem avanços ocasionados por novas estruturas de pensamento. O sujeito em situação de aprendizagem é ativo na busca do saber e na construção de hipóteses para realidade em que vive, sendo o mediador um agente facilitador e desafiador dos processos de elaboração.

Restituir o aprendente de sua capacidade de aprender significa atuar também em sua autoestima. Ao se descobrir capaz o sujeito modifica seus conceitos e representações acerca de si mesmo, se colocando de forma mais segura, apresentando iniciativas, defendendo pontos de vista. Essa transformação é extremamente gratificante aqueles que trabalham como mediadores (professores, psicopedagogos), pois não apenas o sujeito se descobre capaz de aprender, mas também o ensinante se vê capaz de ensinar.

$\mathrm{Na}$ análise dos resultados é necessário considerar a importancia da pesquisa no processo de formação do aluno de IC. Realizar a coleta de dados por meio do diagnóstico psicopedagógico, realizar análise articulando empiria e teoría, participar das discussões e construções do grupo de estudo, planejar, replanejar e desenvolver a intervenção, são momentos proficuos na formação do futuro professor. Conforme relato dos alunos, a práxis psicopedagógica contribui para construção de um olhar mais sistêmico e holístico acerca do sujeito aprendente, assim como para proposições criativas de atividades pedagógicas.

Pode-se concluir que a pesquisa de intervenção enquanto processo de construção do conhecimento contribui com a realidade de todos os envolvidos no contexto educativo (aprendente, ensinante, aluno de IC, grupo de estudo, escola, familia). E ainda promove uma ação articulada entre a universidade, as instituições escolares e a comunidade/sociedade.

\section{Referências}

Miranda, M.I. (2016). Psicopedagogia - trajetória e perspectivas. Uberlândia: EDUFU.

Moroz, M.; Gianfaldoni, M.H.T.A. (2002) O proceso de pesquisa: iniciação. Brasília: Plano.Triviños, A. N. S. (1987). Introdução à pesquisa em ciências sociais: a pesquisa qualitativa em educação. São Paulo: Atlas.

Yin, R.K. (2005) Estudo de Caso: planejamento e métodos. 3ed. Porto Alegre: Book-man. 